\title{
Advocating the use of social media for health education in consideration of the SARS CoV-2 pandemic
}

\author{
Atulya Saxena $^{1 *}$, Zhraa A Alhaboby ${ }^{2}$ and Anoop Saxena ${ }^{3}$ \\ ${ }^{1}$ Oxford Institute of Population Ageing, University of Oxford, United Kingdom \\ ${ }^{2}$ Department of Public Health, University of Wolverhampton, United Kingdom \\ ${ }^{3}$ Department of Educational and Counselling Psychology, McGill University, Canada
}

*Corresponding author: Atulya Saxena, Oxford Institute of Population Ageing, University of Oxford, 66 Banbury Road, Oxford, 0X2 6PR, United Kingdom.

To Cite This Article: Atulya S, Zhraa A A, Anoop S. Advocating the use of social media for health education in consideration of the SARS CoV-2 pandemic. 2020 - 8(6). AJBSR.MS.ID.001334. DOI: 10.34297/AJBSR.2020.08.001334.

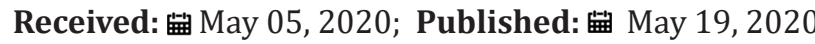

Keywords: SARS CoV-2 pandemic, Covid-19, Health education, Social media

\section{Opinion}

The outbreak of the severe acute respiratory coronavirus 2 (SARS-CoV-2), the causative agent of Coronavirus disease 2019 (COVID-19), began in December 2019 in Wuhan, China [1]. It's progression towards the pandemic by March 2020 [1] and beyond saw variable responses from a number of health agencies and governments that often put to question their motives and health knowledge. From the mention of herd immunity [2] to the suggestion of injecting bleach [3], world leaders demonstrated a lack of knowledge on their own right and worse, an inefficient use of eminent health professionals by their side [4].

The main concerns that were brought to attention were:

1. A delay in government response to control the spread of Covid-19 [5], demonstrating

2. A lack of government confidence in their own measures, [2]

3. A lack of public confidence in government decisions to control the spread of Covid-19, [6]

4. A lack of public compliance with governmental policies in the control of Covid-19,[7]
5. A lack of general understanding of precautions to be taken in controlling the spread of an infectious disease [7], and

6. A lack of public understanding in their responsibility in controlling the spread of an infectious disease [7]

Each of these concerns, propagated in the progression and control of the SARS CoV-2 pandemic, in turn highlight crucial underlying issues that clearly demonstrate the lack of health literacy among populations and professionals; furthered by social media $[8,9]$. Three issues of importance to mention here are those of the mis-education of the population, misconception of a healthy health identity, and learned helplessness. These act against empowering the population in the interest of enhancing the efforts of governing health agencies in promoting the health of the population, and as in the case of Covid-19, protecting the health of the population and saving lives.

One of the main determinants of health and quality of life in a population is health behaviour $[10,11]$. Health behaviour predicts the health status of individuals as well as dictates the resources that are utilized in maintaining a healthy and productive population $[11,12]$. With the rising cost of health care and the monetisation of everything [13], the protection and promotion of health becomes 
extremely important as it directly influences the economic growth performance of any given country [14]. In the case of the SARS CoV-2 pandemic the lack of resources, costs of health care services, and economic challenges faced by countries across the globe have resulted in an unacceptable number of deaths and threatened the economic stability of countries for years to come.

When considering the health and economy of nations, it is important to recognise that in 2020 most countries exist as democratic societies where governing officials and policy makers are chosen from voted members within the population, and organisation structures do not necessitate the need for expertise in medicine or public health for individuals to hold offices and implement policies that influence the health of nations. Often economic and political needs take precedence over health needs. The only way to ensure that health is considered in every policy is by ensuring that health as knowledge is understood and practiced by every person.

Countries across the globe, in 2020, imbibe the reality of governance of the people, by the people and for the people [15]; a reality which can only be fulfilled by a people who understand governance and democracy. And in the manner, that the preservation of democracy requires that every citizen understand the precepts of democracy and her or his rights and duties towards governance, it must be pointed out here that in the interest of the health of nations, it is important for individuals to know what health is and their role and responsibilities towards protecting and promoting the health of these nations. Only this can ensure that health is given priority in the development of policy and that populations comply and complement the efforts of health agencies towards building the health and economic growth of nations.

The issue of the mis-education of the population is of course borne in the lack of the formal health education of populations. However, this has not simply resulted in an absence of health knowledge. During the lockdown, in most countries, the most widespread source of Covid-19 information exchange has been through the use of social media platforms such as Twitter, WhatsApp, Facebook, and Instagram. The content shared through these channels has highlighted the concern of fake news [16-19] and misinformed influencers [20]. The result seen is the confident dispensing of health knowledge from misinformed individuals who are willing to argue for their mis-beliefs but not willing to read a government or reliable health or news agency webpage to understand the pathogenesis or progression of the Covid-19 infection, in the interest of their own health and safety or those that they influence [21].

The lack of an understanding of health also feeds into the issue of the misconception of a healthy health identity. kin to ethnic, age, religious or gender identity, health identity is linked to observations and expectations of one's health, their health knowledge and comparisons to the health of others [22]. Health identity feeds health behaviour [23]. Consequently, misinformed individuals identify as being healthy in their self-perceived health status, encouraging individuals to believe they are healthy for the purpose of transmitting the disease and therefore will not endanger others, as they do not have the virus. They also extend this to others where they believe others to be healthy for the lack of exhibiting symptoms and therefore engage in social activity (forgoing physical distancing measures) that may contribute to the spread of Covid-19; should either of them be carrying the virus.

Finally, an important issue, contributing to the concerns listed above, fostered by the lack of health knowledge, is that of learned helplessness [24,25]. Here individuals believe that they are unable to protect or promote their own health and believe it to be the responsibility of the governing health agencies to do so. However, it can no longer be ignored that the population has changed over the last century, demonstrating a rise in literacy from $12 \%$ in 1820 to $86 \%$ in 2015 [26], the usage of the internet and social media to gain health knowledge [27], and the challenging governing agencies in the interest of their health and human rights [28]; finding learned helplessness an inexcusable burden on health agencies in achieving their goals and even making their efforts of protecting and promoting the health of the population counterproductive.

Health education is the first step towards raising awareness and promoting health [29], to tackle health challenges. The global reach of both the virus and social media indicates that health agencies across the globe must work together through these social media platforms to engage and educate both the population and policy makers, to act as enablers and facilitators of health protecting and promoting behaviours. It is important to note that the SARS CoV-2 pandemic highlights a need for the health education of the population, but not an absence of it. It demonstrates aims education through social media platforms, yet offers them as tried and tested channels, inviting health agencies to take ownership of their responsibility towards the health education of the population, showcasing the pandemic to assert an alarming need for this to be taken seriously.

\section{References}

1. WHO (2020) Director-General's opening remarks at the media briefing on COVID-19.

2. Support The Guardian.

3. Coronavirus: Outcry after Trump suggests injecting disinfectant as treatment.

4. https://www.washingtonpost.com/politics/2020/03/23/trumpsignals-he-wont-abide-by-doctors-coronavirus /

5. https://www.theguardian.com/commentisfree/2020/mar/24/covid19-climate-crisis-governments-coronavirus

6. Trust in Government Lacking on COVID-19's Frontlines.

7. Coronavirus: US faced with protests amid pressure to reopen. 
8. Covid-19: how to be careful with trust and expertise on social media.

9. The pandemic of social media panic travels faster than the COVID-19 outbreak.

10. Mark Conner, Paul Norman (2017) Health behaviour: Current issues and challenges. Psychology \& Health 32: 8, 895-906.

11. The fight against non-communicable diseases in Europe begins by acknowledging that they are linked by common determinants and opportunities for shared policy interventions.

12. Cawley J, Ruhm CJ (2011) Chapter Three - The Economics of Risky Health Behaviors" Handbook of Health Economics, 2(2011): 95-199.

13. The modern trend to monetize everything ignores civilizational wisdom.

14. Bloom David E, David Canning, Jaypee Sevilla (2004) The Effect of Health on Economic Growth: A Production Function Approach. World Development 32: 1: 1-13.

15. https://www.loc.gov/exhibits/gettysburg-address/

16. https://news.un.org/en/story/2020/04/1061592

17. https://www.bbc.co.uk/news/technology-52157202

18. https://www.politico.eu/article/facebook-avaaz-covid19coronavirus-misinformation-fake-news/

19. https://www.theatlantic.com/video/index/579880/instagramwellness/
20. New Study Shows Celebrities Are Key Distributors of COVID-19 Misinformation on Social Media.

21. https: / / www.businessinsider.com/uk-government-fundsinfluencers-fight-coronavirus-misinformation-2020-3?r=US\&IR=T

22. Grabowski D (2015) Health Identity: Theoretical and empirical development of a health education concept. Journal of Sociological Research 6(1): 141-157.

23. Fox NJ, Ward KJ (2008) What are health identities and how may we study them? Sociology of Health \& Illness 30(7): 1007-1021.

24. Hahner K (1989) Learned helplessness: a critique of research and theory. Perspectives on animal Research 1: 1-8.

25. Overmier JB, Molet M (2017) Learned Helplessness. In: Vonk J, Shackelford T (Eds.) Encyclopedia of Animal Cognition and Behavior. Springer, Cham, Switzerland.

26. Roser M, Ortiz-Ospina E (2020) Literacy.

27. Merolli M, Gray K, Martin-Sanchez F (2013) Health outcomes and related effects of using social media in chronic disease management: A literature review and analysis of affordances. Journal of Biomedical Informatics 46(6): 957-969.

28. Morris R (2013) Unjust, inhumane and highly inaccurate: The impact of changes to disability benefits and services-social media as a tool in research and activism. Disability \& Society 28(5): 724-728.

29. Laverack G (2014) Health promotion in context', in: The pocket guide to health promotion. Maidenhead, Open University Press, UK, p. 1-13. 